\title{
https://doi.org/10.48009/1_iis_2006_352-356 \\ IS A HIGH GPA STILL THE MOST IMPORTANT FACTOR FOR JOB OPPORTUNITY? - AN EMPIRICAL INVESTIGATION
}

\author{
Wayne Huang, MIS, Ohio University, Athens, huangw@ohio.edu \\ Hao Lou, MIS, Ohio University, Athens, lou@ ohio.edu \\ John Day, MIS, Ohio University, dayj@ohio.edu
}

\begin{abstract}
The Information Technology (IT) industry changes rapidly. MIS departments need to periodically review and revise their curricula in order to equip their graduates with the most marketable knowledge and skills for future job markets. Little empirical study has been conducted in this area. In this exploratory study, we tried to answer the following research questions: (1) Is GPA still the most important factor for MIS graduates to find a job in this changing business environment? (2) If not, what are other factors that are becoming more important? (3) How can we revise our current MIS curricula to meet the challenges and new requirements from industries in the changing world? In answering the above research questions, a survey was sent to 120 senior MIS students in a big public university. The results of the survey were analyzed and the implications are discussed.
\end{abstract}

Keywords: Job, GPA, MIS, Curriculum, Courses

\section{INTRODUCTION}

Only a few years ago, most students majoring in Management Information Systems (MIS) had multiple job offers, even before their graduation. Now, due to the current economic downturn, some MIS graduates don't find a job six months or even one year after their graduation. According to the National Association of Colleges and Employers (NACE) survey of 230 companies in the USA, 2002 was a difficult year for college graduates seeking employment [6], and many firms were slashing their entry-level hires by $20 \%$ in 2002 as compared to 2001 [2]. The year 2003 was another disappointing year for college graduates $[1,7,11]$, so was the year $2004[5,8,10]$. The year 2005 gave a mixed picture on job market $[3,12]$. In this still soft IT job market, employers are selectively choosing their campus recruits - including entry-level MIS applicants.

Furthermore, the IT industry changes very quickly and MIS departments need to periodically review and revise their curricula in order to equip their graduates with the most marketable knowledge and skills for future job markets. Educational policy makers such as university academic program directors need to understand the key factors influencing the job placement of their graduates. They need to know how their programs can increase the chance of job placement for their students in a very competitive job market.

Historically, larger corporations have valued academic achievement and typically looked for students who graduated from top schools and/or universities with top grade point averages (GPAs) of at least 3.5 out of 4.0. An excellent GPA may normally reflect a high level of material mastery, and traditionally, GPA has been considered by students to be the single most important factor influencing a graduate's job-hunting success [6]. Is GPA still the most important factor for MIS graduates to find a job in this changing job market? If not, what other factors are becoming more important? How can we revise our current MIS curricula to meet the challenges and new requirements of this new job market? Answers to these important questions have not been clearly and thoroughly explored, and there has been little empirical research in the literature.

This research intends to explore these important issues. A survey methodology was adopted and an instrument was used to collect data to find answers to these questions.

As the business environment has changed substantially in the last decade, industries don't look for graduates who have only perfect GPA scores. MIS curricula have also changed with more options being available to the students, including the ability to take a double major or an internship, which can be important vehicles for securing a job after graduation. However, there is relatively little empirical research in the MIS literature that can determine if these factors really have an impact on placement.

\section{RESEARCH METHODOLOGY}

MIS Seniors in the business school of a large state university in the USA were the subjects in this survey. A survey instrument measuring relevant 
constructs was used. Students were asked for demographic background information, the most important factors influencing their job placement, their projection of next year's job market, the number of job offers received so far, the nature of any fulltime job received, etc.

Of the total of 360 students in the MIS program, 120 were seniors who will graduate in 2003. A cover letter written by the MIS department chair was sent to all MIS seniors, inviting them to participate in the survey. The survey questions were put on a website so that the subjects could fill in the questionnaire anytime within one week following the distribution of the cover letter. Sixty-five students volunteered to fill in the questionnaire, which represented a $54 \%$ response rate. Of the 65 filling in the questionnaire, 58 of them were usable. Thirty-four percent of the valid subjects were female and $66 \%$ were male. The next section will report the survey results and the discussion of the implications of the research findings will follow.

\section{RESEARCH FINDINGS}

Figure 1 indicates that most of the students surveyed $(55 \%)$ had a GPA ranging from $3.1-3.49,33 \%$ of them had a GPA ranging from $3.5-4.0$, and $12 \%$ had a GPA ranging from 2.5-3.0. Therefore, the majority of the surveyed students have GPAs above 3.1, which is generally very good. If GPA is still the most important factor in job-hunting, then these students should be more likely to find a job than students whose GPA is lower.

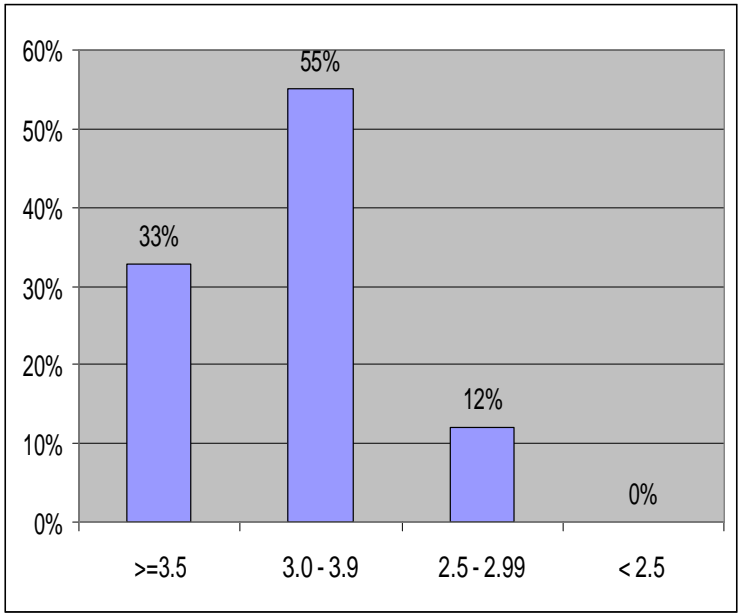

Figure 1. GPA Range of Surveyed Subjects

Figure 2 shows that when the survey was conducted in 2002, nearly $70 \%$ of MIS seniors did not have a job offer, about $19 \%$ received one job offer, about
$5 \%$ received two job offers, $3 \%$ received three job offers, and $3 \%$ received four job offers. When considering that most of these MIS students had good GPAs, the job market for MIS graduates was quite bad in 2002. Considering this, one key question was whether their high GPAs helped them in job-hunting?

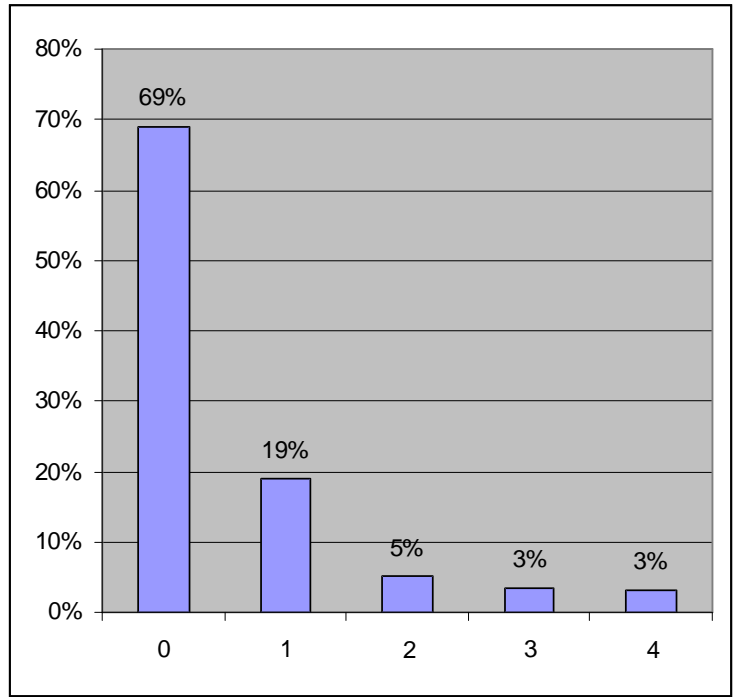

Figure 2. The Number of MIS Job Offers Received by MIS Seniors

Figure 3 shows that most students (41\%) believe that internship experience is the single most important factor influencing their success in finding a full time job after graduation. This is surprising because it is very different from the traditional view that GPA is the single most important factor in finding a full time job [6]. In fact, only $2 \%$ of the surveyed students think that a high GPA is the most important factor in finding a full time job. Further, 24\% of them think that communication skills are the most important factor for them in finding a full time job, and $21 \%$ consider technical skills (such as network skills, java programming, and e-commerce systems development skills) as the most important factor. These findings reflect prevailing views of current MIS students, which should have an important impact on the direction of MIS curriculum in the near future. 


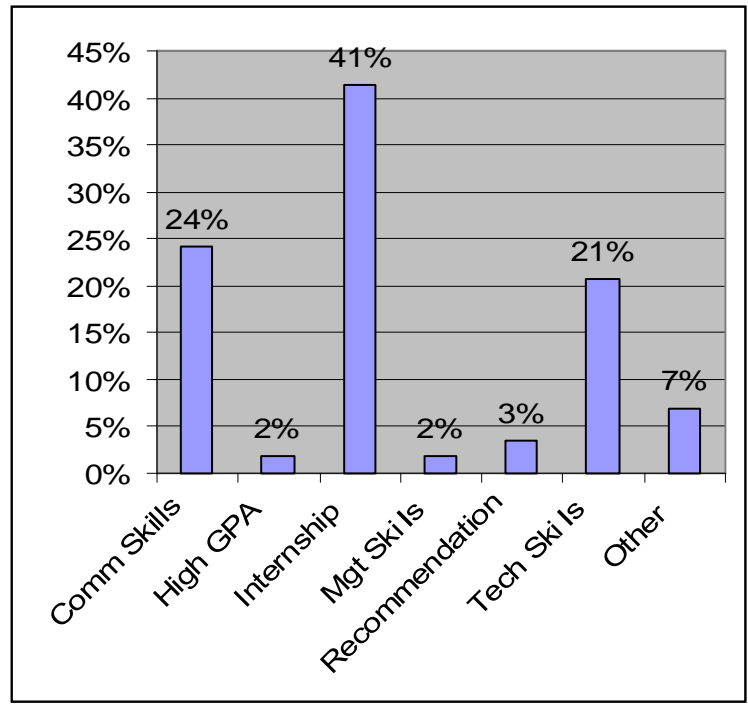

Figure 3. The Most Importance Perceived Factor Influencing Job Hunting

While most students had not found a job when the survey was conducted, many of them had done internships before. We further asked students about their opinions of whether their MIS courses would be useful in their internship work. Figure 4 reveals that $22 \%$ of students thought that the MIS courses offered at the university were of only a little help in their internship work while $18 \%$ of students reported that their MIS courses were of no use to their internship work at all. Nearly $60 \%$ students reported that the MIS courses learned at the university were of some help or a great help in their internship work. Hence, it seems clear that the current MIS curriculum may not match internship job skills very well. This may indicate the need for a revision of the curriculum.

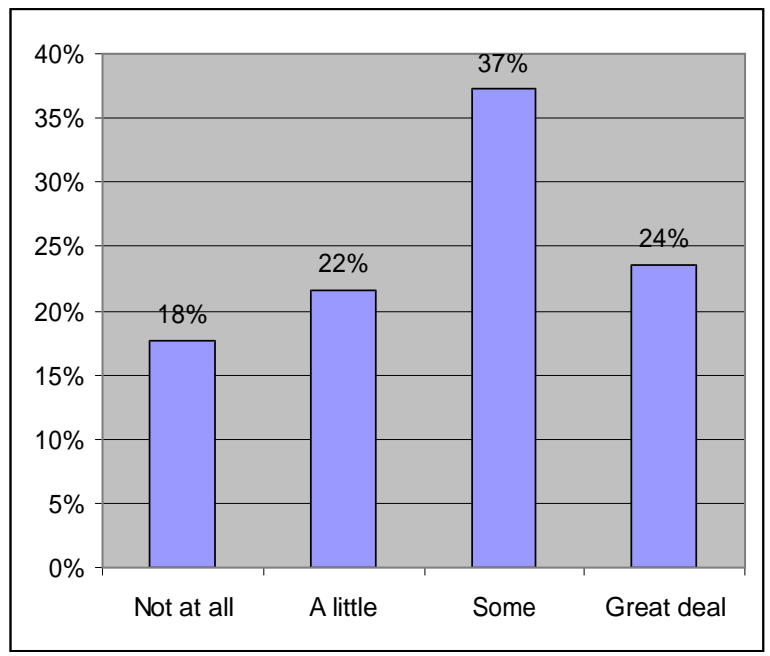

Figure 4. Do MIS Courses Help with MIS Related Internships?
Figure 5 shows that, for those who were offered a first-time MIS job (including MIS internship jobs), the top four types of jobs offered were: systems analysts $(32 \%)$, MIS related jobs that were not in the list (20\%), web design/development (16\%) and programming $(16 \%)$.

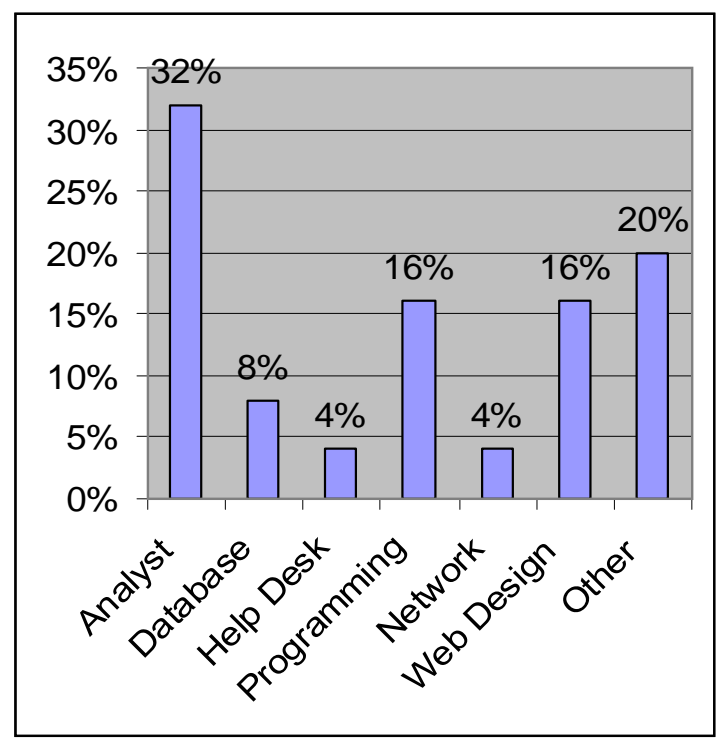

Figure 5. The Percentage of Types of Full-Time Jobs Offered

Figure 6 shows that $45 \%$ of the students were offered the jobs that were not MIS-related. This was another surprising finding. This indicates that $45 \%$ of the jobs offered require knowledge and skills other than MIS, which could make the change of MIS curriculum much more difficult and complicated than we previously thought.

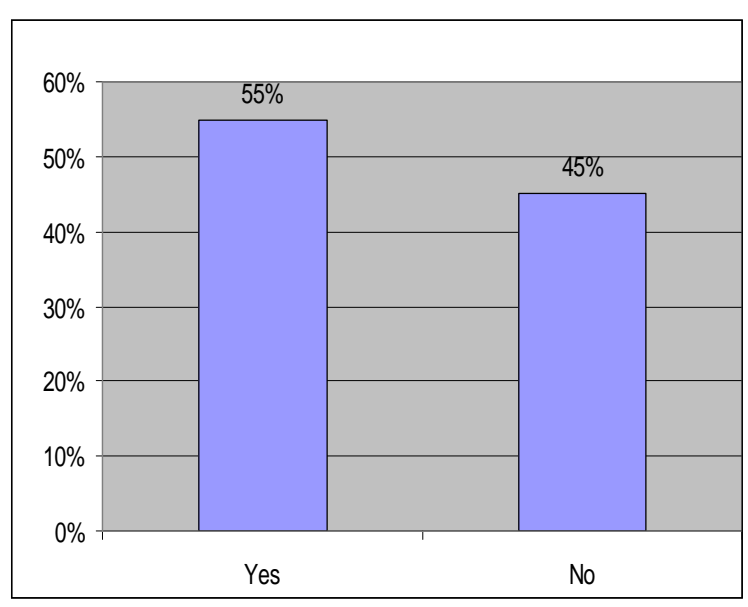

Figure 6. Was your Job Offer MIS-related? 
Figure 7 shows that the traditional recruiting companies such as IT consulting companies, computer technology vendors, manufacturing firms, retailing firms, financial firms, health care related firms, and delivery service related firms are not recruiting most MIS graduates in 2002. Twenty-five percent of students reported that they were recruited by companies other than those traditional firms that were more likely to offer MIS/IT related jobs. The health care related firms offered $20 \%$ of the jobs, big IT consulting firms and financial firms each offered $15 \%$ of the jobs, and manufacturing firms offered $10 \%$ of the jobs. These are the four biggest recruiters of MIS graduates, and where MIS seniors should focus their job-hunting in the future.

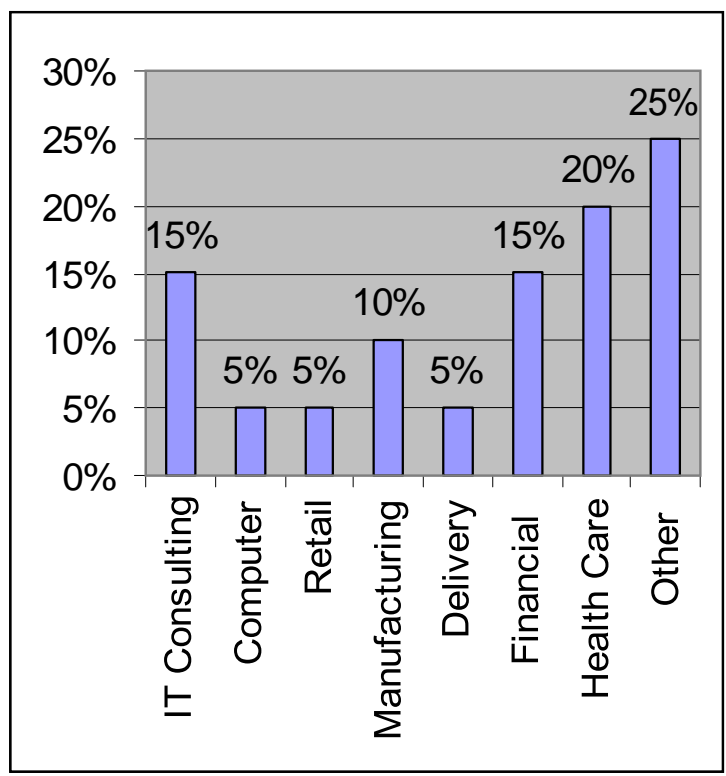

Figure 7. The Percentage of Types of Corporations Hiring MIS Graduates

\section{DISCUSSION AND IMPLICATIONS}

This exploratory investigation reported a few interesting research findings. Contrary to the traditional belief that GPA is the single most important factor in finding a full time job for students, in this study students felt that it was actually the least important factor among the seven factors studied (only $2 \%$ of students considered it important to their job-hunting). Instead, internship, communication skills, and information technology skills are the top three factors listed by MIS graduates. It seems that the traditional curriculum providing a more academic focus assessed solely by GPA may not work well any more. On the other hand, a recent survey from the employer's side also confirmed the findings in this study that communication skills (both written and verbal) has topped the list as the most important job skill since 1999, and GPA only functioned as a cut-off mechanism where employers normally short-listed students with GPA greater than 3.0. After the cut-off, GPA wouldn't play a very important role in determining job offers [9].

Further, nearly $40 \%$ of the students reported that the current MIS courses did not help them much in their job-hunting and $18 \%$ of the students even thought that the MIS courses did not help them at all in the job market. Therefore, the current MIS curriculum needs to be re-visited and changed accordingly to meet the new requirements of the job market.

More specifically, current MIS courses may need to be revised to add in more components that require communication skills. For example, group projects should be encouraged in a new MIS curriculum so that students will learn and practice more communication skills in group work. Further, presentations from students should be part of the whole assessment system in a course, which would enhance communication skills as well. Also, to support the belief that technical skills are still important, especially skills related to the latest technologies, courses or course content could be added into existing MIS programs, such as Java, C++, ASP.Net, network security, Unified Modeling Language (UML), and e-commerce system developmental tools. Even faced with the challenge of IT outsourcing, some technical skills related to the latest information technologies may be still necessary because the success of IT outsourcing projects depends on strong project management and a good project manager needs to understand and be knowledgeable about the latest information technologies to manage IT outsourcing projects better.

One component of the MIS curriculum is largely missing: ethics and integrity of IT professionals. Some current MIS programs don't offer specific courses dealing with this issue, which has been considered as one of the top two factors determining job offers from employers [4]. This big gap should attract attention from MIS educators. This is not only a problem of meeting the requirement of employers, but also an important issue of training and developing qualified IT professionals who can be trusted to serve the society in the future. This issue should not be delayed further and actions should be taken as soon possible. 
As shown in Figure 6, 45\% of the students received job offers that were not directly MIS-related. In other words, those companies offered MIS graduates jobs that required other knowledge and skills in addition to direct MIS knowledge and skills. Consequently, the above-suggested revision of the current MIS curriculum cannot solve this problem alone. One possible innovative method could be a double-major program that is being set up or has been set up in some business schools. For example, given that the top recruiting companies for MIS graduates include financial firms, health care related firms and manufacturing firms (see Figure 7), the MIS department can work with departments of finance, accounting, or engineering to offer double major programs to students.

Even though it is encouraging to see that the IT/IS job market is starting to recover, MIS programs face new challenges ahead. Traditional emphasis on simple academic performance as represented by a high GPA will not help MIS students in the current job market. Regardless of whether we are ready, many existing MIS programs may have to be changed to help MIS students locate internships, complete double majors, and improve communication and technical skills in the near future. MIS program directors and/or professors should take actions now to make the necessary changes so that their MIS programs could survive and develop in the $21^{\text {st }}$ century.

Like other research work, the current survey study has its limitations. First, the survey was conducted in one university. Second, future studies can also conduct a survey on the same issue from the perspective of recruiters.

\section{REFERENCES}

1. CNN News on Education, (April 14, 2003), http://www.cnn.com/2003/EDUCATION/04/14 /life.students.reut/

2. Dash, J. (2002). Where the jobs are: Entry-level IT candidates face a tough market, but there are opportunities out there if you look in the right places. Computer World, May 27, p.26.

3. Eckle, J. (Feb 7, 2005). Market Roundup. Computerworld, 39(6), p38, 1/3p.

4. Giordani, P. (Oct 26, 2004). Employers and colleges differ on student development and assessment. National Association of Colleges and Employees (NACE) Press Release.

5. Gomolski, B. (Oct 18, 2004). What to Tell The Kids. Computerworld, 38(42), p34, 4/5p.

6. Hames, M. (Sept 30, 2002). Right strategies can make you stand out form crowd. Electronic Engineering Times, p.94.

7. Hobson, M. (2004). Grim Outlook for Grads: Class of 2003 Steps into Shaky Job Market. $A B C$ News, http://abcnews.go.com/sections/GMA/Business/ GMA030528 American_job_hunt.html (accessed on Feb. 15th, 2004)

8. Hoffman, T. (Nov 29, 2004). CIOs, Recruiters Split On IT Job Prospects. Computerworld, $38(48), \mathrm{p} 12,3 / 5 \mathrm{p}$.

9. Koncz, A. (Jan 20, 2005). Communication skills, honesty/integrity top employers' 'Wish List' for job candidates. National Association of Colleges and Employees (NACE) Press Release.

10. Melymuka, K. (Sept 27, 2004). High-Tech Bust. Computerworld, 38(39), p48, 1/3p.

11. PBS News. (June 6, 2003). Report card: The job market. A News Hour with Jim Lehrer. http://www.pbs.org/newshour/bb/education/janjune03/jobmarket_06-06.html

12. Tennant, D. (Jan 17, 2005). C-F-Uh-oh. Computerworld, 39(3), 14. 